Tema: Engenharia de Superfície

\title{
ENSAIOS TRIBOLOGICOS PARA OBTENÇÃO DO COEFICIENTE DE ATRITO DE UM AÇO FERRAMENTA COM TRATAMENTOS SUPERFICIAIS DE NITRETAÇÃO A PLASMA E REVESTIMENTO TiCN*
}

\section{Resumo}

Luciano Aparecido Kempski ${ }^{1}$ Giovanni Rocha dos Santos ${ }^{1}$ Alexandre da Silva Rocha ${ }^{2}$ Uilian Boff' Rodrigo Afonso Hatwig ${ }^{1}$ Germano Carvalho Rosa ${ }^{3}$

O ferramental utilizado em processos de conformação é de grande interesse da Engenharia de Superfícies devido às características tribológicas específicas encontradas nestes processos. Portanto busca-se sempre melhorar o ferramental para se obter menores coeficientes de atrito, desgaste e adesão de material sobre a superfície da ferramenta, sendo empregadas diversas técnicas de tratamentos superficiais como a nitretação e os revestimentos depositados via PVD. Uma variável importante do par tribológico é o coeficiente de atrito desenvolvido entre as superfícies em contato nos processos de conformação a frio, portanto foram realizados ensaios de pino-sobre-disco e ensaios DST, para determinação de coeficientes de atrito em pares tribológicos. Desta forma, chapas de aço inoxidável austenítico AISI 304 foram conformadas sobre uma superfície de um aço ferramenta DIN X100CrMoV8-1-1, com o propósito de se conhecer o atrito desenvolvido entre os materiais. As amostras foram nitretadas a plasma e ou revestida com TiCN, posteriormente, a caracterização da microestrutura e as propriedades avaliadas através de ensaios mecânicos e tribológicos. O ensaios proporcionaram obter valores de coeficiente de atrito para as condições de tratamentos e lubrificação utilizados e as análises dos resultados mostram um aumento da dureza superficial das amostras tanto nitretadas quanto revestidas com TiCN e uma redução do coeficiente de atrito significativa quando se faz uso do revestimento.

Palavras-chave: Ensaios tribológicos; Coeficiente de atrito; Nitretação a plasma; Revestimento TiCN.

\section{TRIBOLOGICAL TESTS FOR OBTAINING THE COEFFICIENT OF FRICTION OF A STEEL TOOL WITH TREATMENT SURFACE OF PLASMA NITRIDING AND TICN COATING}

\begin{abstract}
The tooling used in forming processes is of great interest to Surface Engineering due specific tribological characteristics found in these processes. Therefore it is always seeking to improve the tooling to provide lower coefficients of friction, wear and adhesion of the material on the surface of the tool, being employed various techniques of surface treatments such as nitriding and coatings deposited by PVD. An important variable of the tribological pair is the coefficient of friction developed between the contact surfaces in the process of cold forming, so testing pin- on - disk and BUT tests to determine the coefficient of friction in tribological pairs were performed . Thus, stainless steel AISI 304 austenitic were processed on a surface of a tool steel DIN X100CrMoV8 1-1, with the purpose of knowing the friction developed between the materials. The samples were plasma nitrided and coated with TiCN or later, the characterization of the microstructure and the properties evaluated through mechanical and tribological. The tests gave obtain coefficients of friction for the conditions of treatment and lubrication used and analyzes of the results show an increase surface hardness in both samples of the nitrided and coated with TiCN and a significant reduction in coefficient of friction when use is made of the coating .

Keywords: Tribological tests, Friction coefficient, Plasma nitriding, Coating TiCN.




\section{INTRODUÇÃO}

Nitretação é o conceito genérico aplicado às técnicas nas quais se introduz nitrogênio na superfície de um material, normalmente metálico, com o objetivo de conferir-Ihe propriedades específicas. Como exemplo destas propriedades, pode-se citar alta dureza superficial, resistência ao desgaste, resistência à fadiga (relacionada com baixa sensibilidade ao entalhe) e aumento da resistência à corrosão. O incremento destas propriedades é fator de aumento da vida útil, durabilidade e confiabilidade de peças, ferramentas e componentes metálicos.

O plasma, que dá nome ao processo, possui características particulares que permitem seu uso para a inserção de átomos em uma superfície. Ele consiste em um gás contendo espécies neutras e eletricamente carregadas, como elétrons, íons positivos, íons negativos, átomos e moléculas. O plasma deve ser eletricamente neutro: logo, a soma da carga de elétrons e íons negativos deve igual à de íons positivos.

O resultado do processo é o surgimento de duas zonas distintas na superfície nitretada. A zona mais externa é chamada de camada de compostos, ou camada branca. Esta camada é constituída de dois tipos de nitretos: o Y' $\left(\mathrm{Fe}_{4} \mathrm{~N}\right)$ e o $\varepsilon\left(\mathrm{Fe}_{2-3}(\mathrm{C}) \mathrm{N}\right)$. Sua principal característica é possuir dureza muito elevada. Abaixo da camada de compostos, situa-se a zona de difusão, onde há átomos de nitrogênio difundidos para o interior da rede cristalina de átomos de ferro.

Nesta região, há um gradiente decrescente da concentração de nitrogênio em direção ao núcleo do material nitretado, o que ocasiona também um gradiente de propriedades como dureza e tenacidade. A composição e a espessura destas zonas podem ser manipuladas através do controle das variáveis envolvidas. Estas variáveis são a temperatura, a composição da mistura gasosa, o tempo, a diferença de potencial aplicada e a densidade de corrente. A mistura gasosa e a temperatura são determinantes para haver ou não formação de camada branca e de quais tipos de nitretos ela será constituída. Conforme o que foi exposto nos parágrafos anteriores, o processo é, portanto, altamente confiável e possui grande aplicação na melhoria de propriedades de materiais de uso industrial.

Os principais parâmetros estudados relacionados a filmes finos nanoestruturados depositados via PAPVD (Plasma Assisted Physical Vapour Deposition), para uma aplicação de sucesso, são: o acabamento superficial da ferramenta, o qual deve ser o melhor possível apresentando uma rugosidade baixa; quando no caso de tratamentos dúplex, não deve-se produzir camada de compostos nos substratos nitretados; devem estar presentes tensões residuais compressivas nas camadas nitretadas e nos revestimentos; pós-tratamentos mecânicos nos revestimentos são mandatórios para revestimentos PVD produzidos pela técnica de evaporação por arco catódico; adequado suporte mecânico deve ser dado pela zona de difusão e pelo material base, e os revestimentos devem possuir um coeficiente de atrito o mais baixo possível.

Tipicamente, estes processos são utilizados para formação de filmes com espessuras que variam de poucos nanômetros até milhares de nanômetros (ou micrometros), no entanto, também podem ser usados para formar filmes multicamadas ou com composição gradual.

Este revestimento foi escolhido para este estudo, pois tem como propriedades principais a alta resistência ao desgaste e a capacidade de reduzir seu coeficiente de atrito significativamente em serviço através da ativação do efeito de running-in. 


\section{MATERIAIS E MÉTODOS}

\subsection{Caracterização do Material Base - Composição Química, Microestrutura e Dureza}

$\mathrm{Na}$ Tabela 1 é apresentada a composição química nominal do aço DIN X100CrMoV8-1-1 utilizado neste trabalho conforme especificação do fabricante, e também a composição química medida em uma das barras adquiridas.

Tabela 1 - Composição química do aço DIN X100CrMoV8-1-1 (\% em massa).

\begin{tabular}{|l|c|c|c|c|c|}
\hline Elemento de Liga & $\mathbf{C}$ & $\mathbf{S i}$ & $\mathbf{C r}$ & $\mathbf{V}$ & Mo \\
\hline Composição nominal (\% em massa) & 1,00 & 0,90 & 8,0 & 1,60 & 1,10 \\
\hline Composição amostra (\% em massa) & 1,00 & 0,95 & 7,9 & 1,55 & 1,06 \\
\hline
\end{tabular}

Foi realizada preparação metalográfica do material base para identificação da microestrutura resultante após tratamento térmico. A microestrutura encontrada (Figura 1) é típica de um aço ferramenta, onde pode-se visualizar em microscópio ótico a presença de martensita revenida, carbonetos primários e secundários.

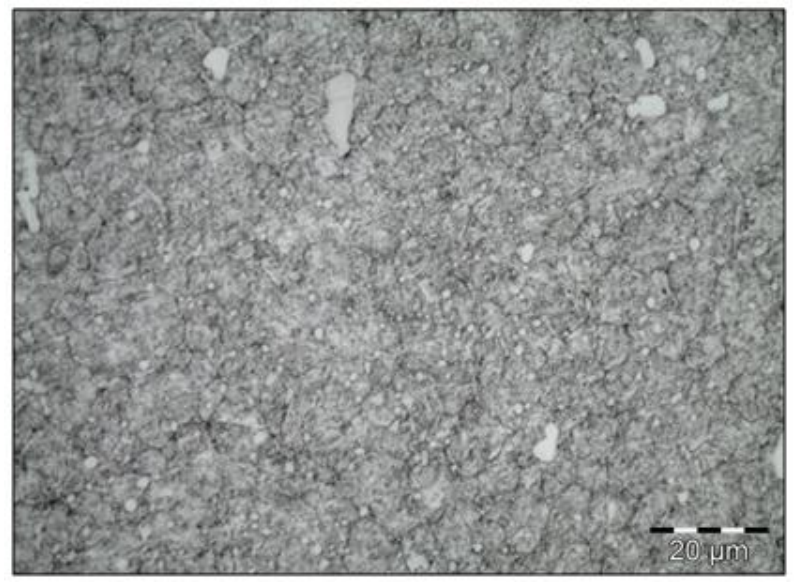

Figura 1 - Micrografia de uma seção transversal do aço após tratamento térmico. Ataque: Nital $2 \%$. Aumento: 1000x.

\subsubsection{Confecção de amostras (discos e pinos)}

Foram cortadas amostras com geometria final de $31 \mathrm{~mm}$ de diâmetro e $5 \mathrm{~mm}$ de espessura. Depois de usinados, os discos foram retificadas para obtenção de uma superfície plana, logo em seguida foram tratadas termicamente (têmpera e triplo revenimento) e a dureza média de $61 \mathrm{HRC}$ foi obtida.

Os pinos também foram usinados à partir de barras do mesmo material, em seguida passaram pelo tratamento térmico de têmpera e triplo revenimento obtendo-se valor médio de dureza de $60 \mathrm{HRC}$. Após tratamento térmico, diâmetro de $13 \mathrm{~mm}$ (diâmetro menor indicado na Figura 2) foi retificado para remoção de sobremetal e ajuste de dimensional. Os pinos tiveram a superfície do seu diâmetro menor, a qual é a região útil para ensaio DST, lixadas com lixa 600 e 1000 mesh e depois polidas com pasta de diamante de $4 \mu \mathrm{m}$ e $1 \mu \mathrm{m}$. 

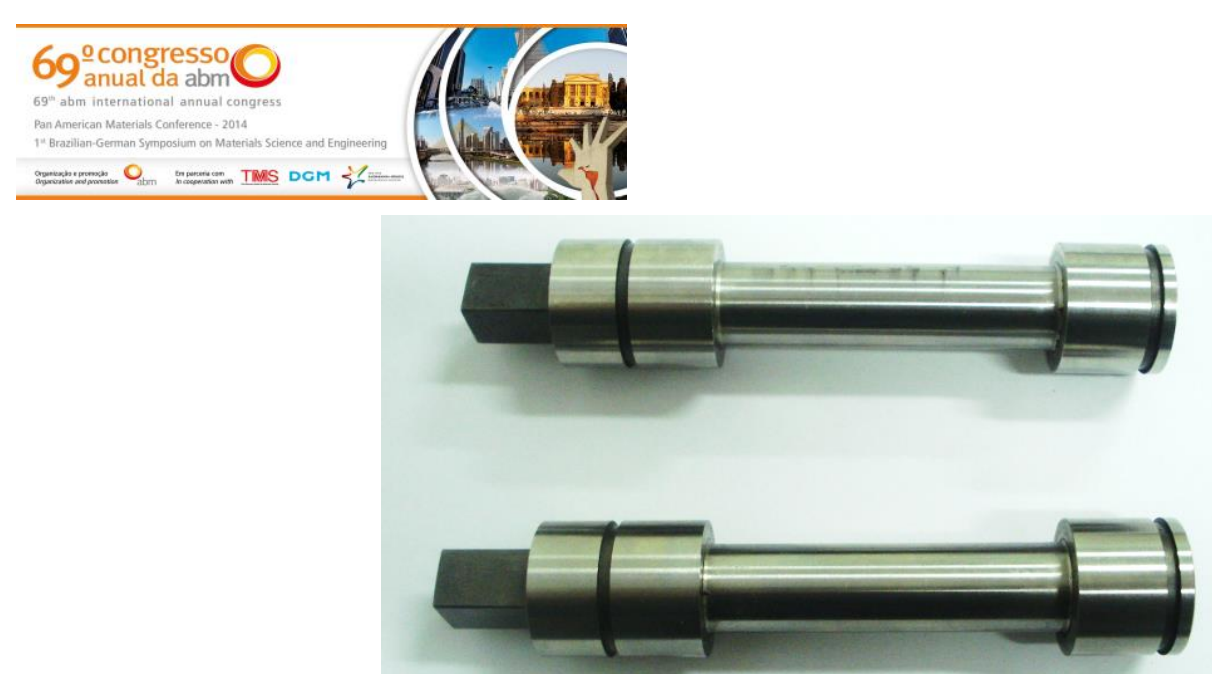

Figura 2 - Pinos utilizados para o ensaio de dobramento sobre tensão.

\subsection{Nitretação à Plasma}

Os parâmetros utilizados no processo de nitretação à plasma foram monitorados e são apresentados na Tabela 2. Dois diferentes tempos na etapa de nitretação foram utilizados (2,5 e 5 horas), os demais parâmetros todos foram mantidos constantes.

Tabela 2 - Parâmetros utilizados nos processos de nitretação à plasma.

\begin{tabular}{|c|l|l|l|l|l|}
\hline Etapas & Bombeamento & Pulverização & $\begin{array}{l}\text { Aquecimento e } \\
\text { Pulverização }\end{array}$ & \multicolumn{1}{|c|}{ Nitretação } & Resfriamento \\
\hline Pressão & Até 0,05 mbar & 1 mbar & 4 mbar & 4 mbar & 0,05 mbar \\
\hline Gás & Nenhum & Hidrogênio & Argônio & $\begin{array}{l}5 \% \text { Nitrogênio + } \\
95 \% \text { Hidrogênio }\end{array}$ & Nenhum \\
\hline Temperatura & Ambiente & Aprox. $200^{\circ} \mathrm{C}$ & $450^{\circ} \mathrm{C}$ & $450^{\circ} \mathrm{C}$ & $\begin{array}{l}\text { Até se atingir a } \\
\text { temperatura } \\
\text { ambiente }\end{array}$ \\
\hline Tempo & $\begin{array}{l}\text { Até se atingir } \\
\text { pressão mínima } \\
\text { de 0,05 mbar }\end{array}$ & 45 min. & $\begin{array}{l}\text { Até se atingir } \\
\text { temperatura de } \\
450^{\circ} \mathrm{C}\end{array}$ & $\begin{array}{l}2,5 \text { horas e } 5 \\
\text { horas }\end{array}$ & Aprox. 3 horas \\
\hline
\end{tabular}

Um disco ou pino de mesma geometria foi utilizado para medição de temperatura através da introdução de um termopar tipo $\mathrm{K}$ até uma distância de aproximadamente $10 \mathrm{~mm}$ a partir da superfície das amostras. Os corpos de prova e os pinos foram colocados de forma simétrica (conforme apresentando na Figura 3) fazendo com que sua distância em relação à parede da câmara fosse a mesma. Uma chapa plana em aço inoxidável ferrítico serviu como base de apoio, fazendo com que a superfície de interesse ficasse exposta, permitindo sua nitretação.

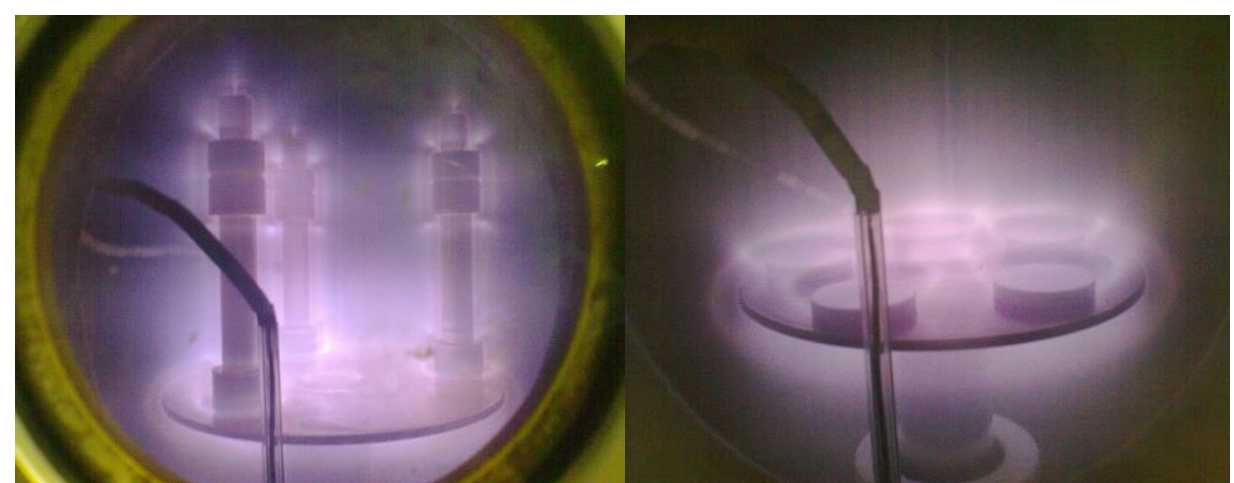

Figura 3. Nitretação dos pinos (esquerda) e nitretação das amostras (direita). 


\subsection{Aplicação de Revestimento}

A deposição do revestimento TiCN foi realizada pela empresa Oerlikon Balzers Revestimentos Metálicos Ltda. O processo utilizado pelo fornecedor de revestimentos é PAPVD (Plasma Assisted Vapor Deposition) e possui o método de arco catódico para evaporação dos alvos, os quais tem concentração de $99,9 \%$ de titânio. O esquema abaixo representa o processo.

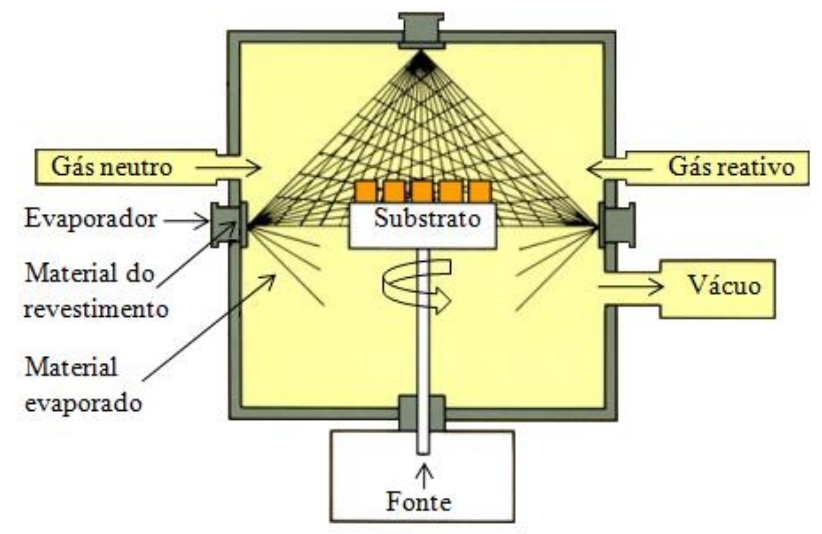

Tabela 3 - Parâmetros utilizados nos processos de revestimento.

\begin{tabular}{|c|c|c|c|c|}
\hline Etapas & Bombeamento & $\begin{array}{c}\text { Aquecimento e } \\
\text { Pulverização }\end{array}$ & Deposição & Resfriamento \\
\hline Pressão & Até aprox. $10^{-6} \mathrm{mbar}$ & $0,5 \mathrm{mbar}$ & 0,02 a 0,03 mbar & 300 mbar \\
\hline Gás & Nenhum & Argônio + Hidrogênio & $\begin{array}{l}\text { Acetileno+ } \\
\text { Nitrogênio +Argônio }\end{array}$ & Nitrogênio \\
\hline Temperatura & Ambiente & $450^{\circ} \mathrm{C}$ & $450^{\circ} \mathrm{C}$ & $\begin{array}{l}\text { Até se atingir a } \\
\text { temperatura ambiente }\end{array}$ \\
\hline Tempo & $\begin{array}{l}\text { Até se atingir } \\
\text { pressão mínima de } \\
10^{-6} \mathrm{mbar}\end{array}$ & $60 \mathrm{~min}$. & 35 min. e $80 \mathrm{~min}$. & Aprox. 2 horas \\
\hline Bias & - & - & $-50 \mathrm{Va}-250 \mathrm{~V}$ & - \\
\hline
\end{tabular}

\subsection{Ensaio de Dobramento sob Tensão}

O ensaio de dobramento sob tensão (DST - do inglês BUT - Bending Under Tension Test) consiste em dobrar uma tira de chapa através de um pino de raio prédeterminado e sobre esse pino fazer a chapa deslizar. Para isso, há a aplicação de uma força em uma das extremidades da chapa para que haja o movimento relativo entre a chapa e o pino.

A máquina usada para medição de atrito é mostrada na Figura 4. Neste equipamento, existem dois cilindros hidráulicos que tem a função de fazer uma tira de chapa deslizar sobre um pino. Esses cilindros hidráulicos foram montados em uma estrutura triangular que tem como objetivo a diminuição da influência da vibração dando mais estabilidade para transmitir as forças durante o ensaio.

$\mathrm{Na}$ outra extremidade é aplicada uma força contraria ao movimento com o objetivo de tencionar a chapa e poder-se variar a pressão de contato incidente sobre o pino. A força que gera o movimento é chamada de força de atuação e a força que é aplicada no sentido contrario é chamada de força de contra-tensão.

$O$ pino de raio $r$ tem a função de simular o atrito na passagem do raio da matriz de estampagem, por ser nessa região que as tensões são maiores. 


\section{(a)}
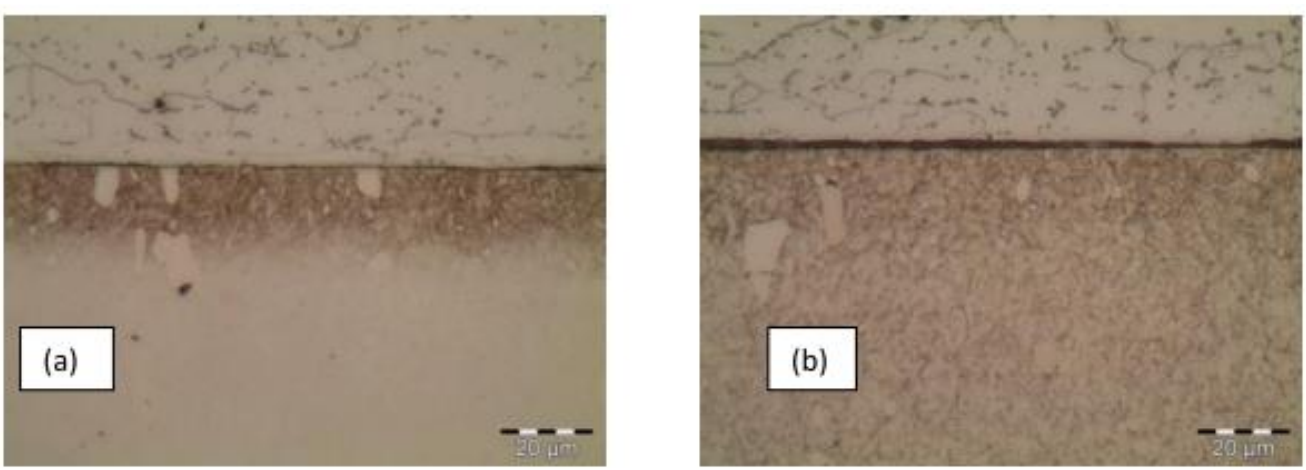

Figura 6. Micrografia mostrando presença de zona de difusão na amostra nitretada com (a) 2,5h e (b) 5h de tratamento. Ataque: nital 2\%. Aumento: 1000x.

\subsection{Dureza Superficial e Perfil de Microdureza}

Para medição da dureza superficial das camadas nitretadas utilizou-se um microdurômetro, a escala de medição foi a Vickers e as cargas aplicadas foram de 25, 50, 100, 200, 500 e 1000g; foram feitas um total de 5 medições por disco para cada condição de nitretação.

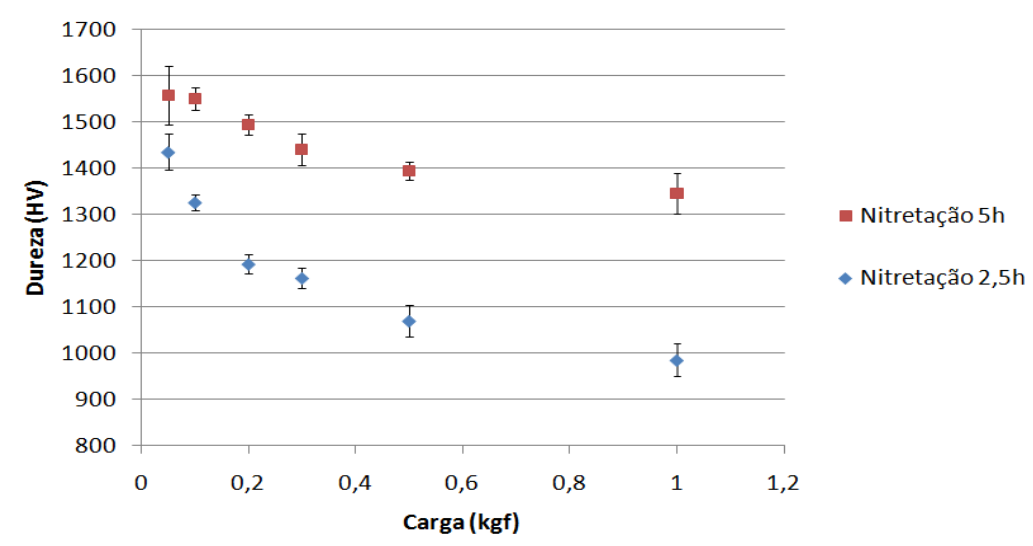

Figura 7. Valores de microdureza superficial em função das cargas aplicadas no ensaio para os tratamentos.

Para obtenção dos perfis de microdureza foi utilizada como referência a norma ISO 4970 , utilizou-se carga de $200 \mathrm{~g}$ na escala Vickers e o critério adotado para determinação da profundidade total de camada nitretada foi dado como sendo a distância a partir da superfície até a profundidade em que dureza núcleo atingida.

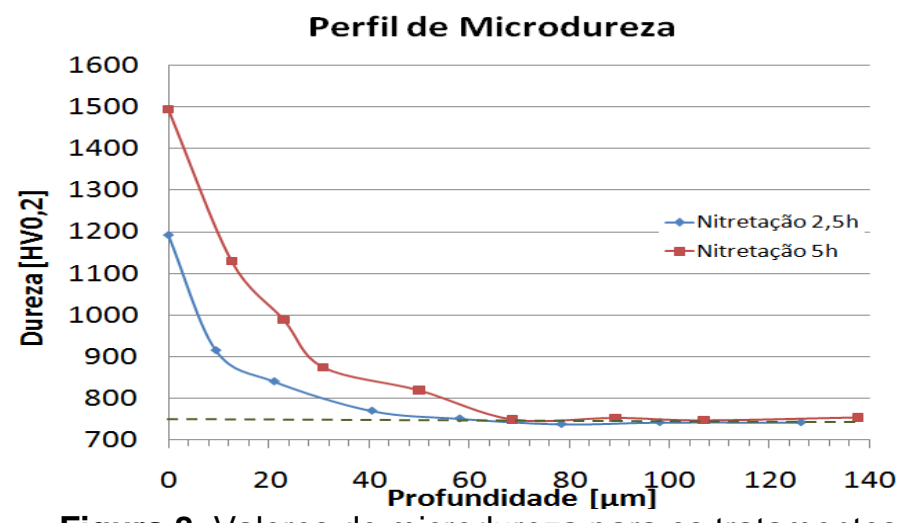

Figura 8. Valores de microdureza para os tratamentos. 


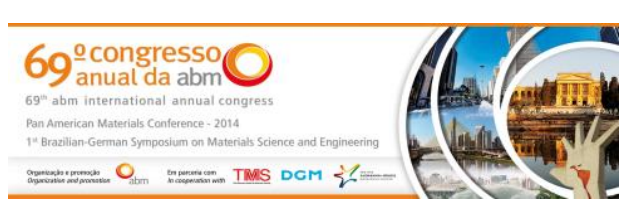

As Figuras 7 e 8 mostram os resultados de microdureza superficial e perfil de microdureza, respectivamente. No gráfico relacionado a dureza superficial pode-se demonstrar o aumento de dureza obtida quando são utilizados tempos maiores de nitretação do substrato, onde mostram valores de até aproximadamente $1500 \mathrm{HV}$ para tratamentos de 5 horas de nitretação.Em relação ao perfil de microdureza obtido para os tratamentos e considerando a linha tracejada como uma aproximação da dureza do substrato tem-se e como resultado a profundidade de camada de difusão de 60 e $70 \mu \mathrm{m}$ para os tratamentos de nitretação a plasma de 2,5 e 5 horas, respectivamente.

\subsection{Perfil de Composição Química - GDOES (Glow Discharge Optical Spectroscopy)}

A Figura 9 mostra a variação da composição química a partir da superfície para as amostras revestida, onde a formação do revestimento de TiCN pode ser verificada através dos resultados obtidos no ensaio de GDOES, o qual revela a presença dos elementos químicos $\mathrm{Ti}, \mathrm{C}$ e $\mathrm{N}$. A espessura de camada de revestimento para a amostra TiCN 1 medida é de aproximadamente 1,5 $\mu \mathrm{m}$.

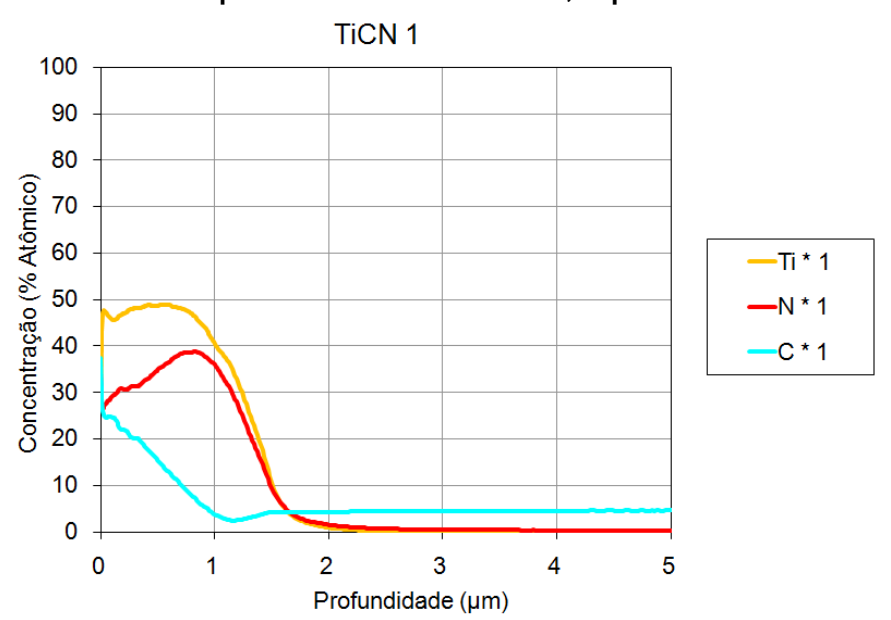

Figura 9. Valores de concentração (\% Atômico) em função da profundidade para TiCN1.

$\mathrm{Na}$ Figura 10 o perfil de composição química revela espessura de camada de revestimento para a amostra TiCN 2 de aproximadamente 2,5 $\mu \mathrm{m}$.

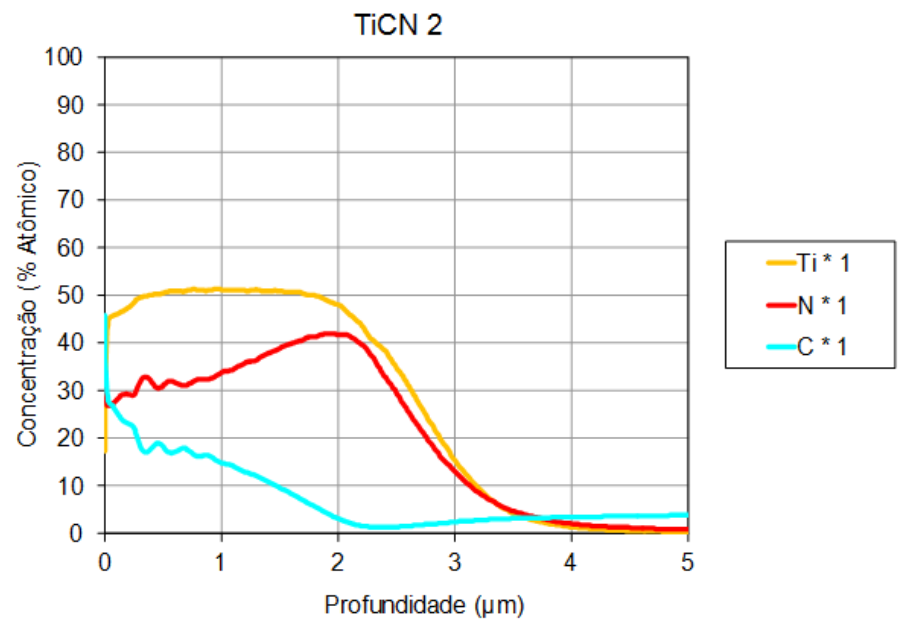

Figura 10. Valores de concentração (\% Atômico) em função da profundidade para TiCN2. 


\subsection{Adesão}

Todas as amostras revestidas são submetidas ao ensaio de adesão pela técnica da indentação Rockwell C. Este é um método largamente utilizado, tanto em escala laboratorial quanto industrial, para qualificação da adesão de filmes finos sobre substratos de aço.

Ele consiste na aplicação de uma carga de 150kgf com um indentador de diamante cônico (ensaio de dureza Rockwell C convencional) sobre a superfície plana de uma amostra revestida. O teste é regido pela norma alemã VDI 3198.

A impressão resultante é observada em microscópio ótico com um aumento de 100x e o padrão de trincas e desplacamento do revestimento nas bordas da impressão são comparados com padrões visuais da norma, e são classificados em uma escala de HF1 a HF6, como pode ser visto na Figura 11.

Quando o aspecto identificado variar entre HF1 e HF4 a adesão é considerada satisfatória e para padrões HF5 e HF6 a adesão não possui qualidade adequada.
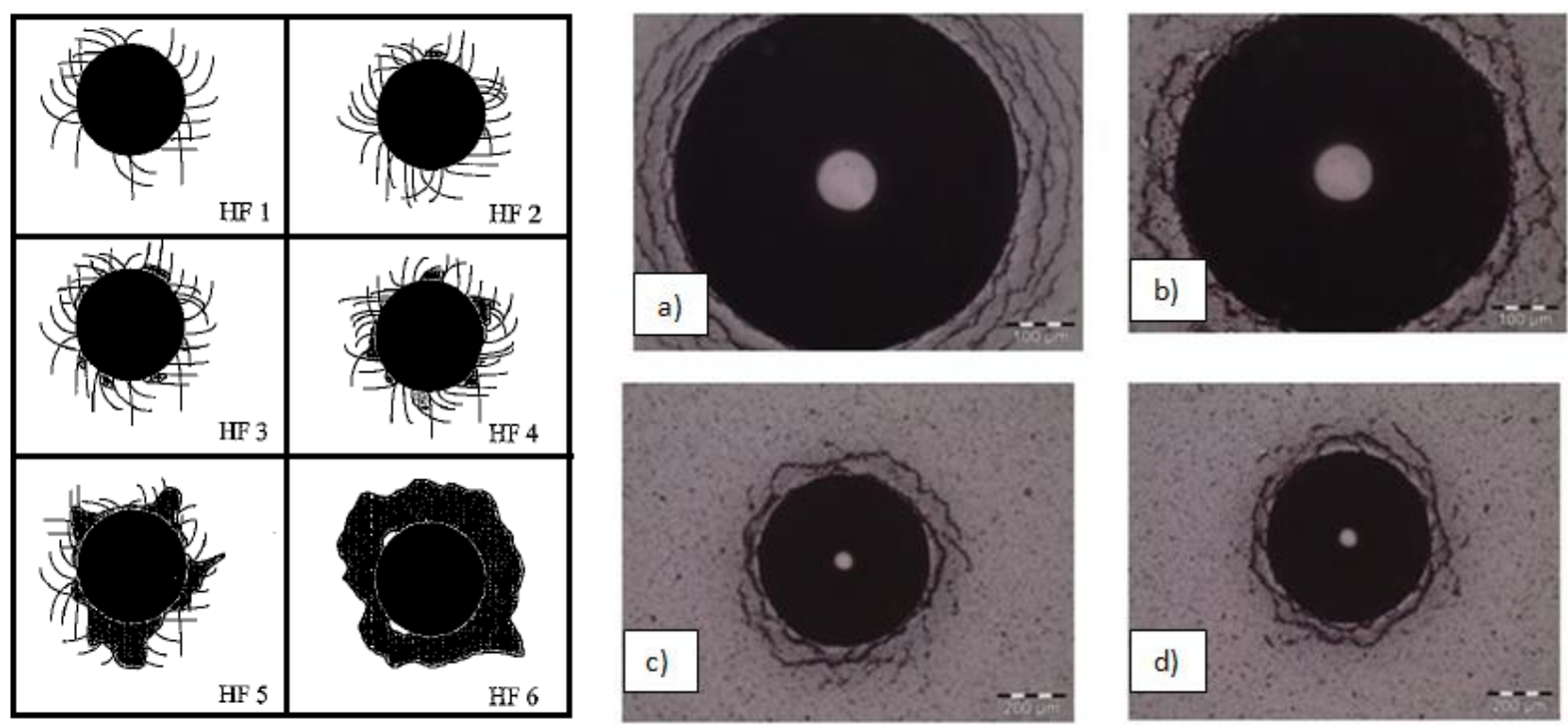

Figura 11. Indentações Rockwell $C$ dos filmes de TiCN depositados, onde (a) e (b) revestimento TiCN1, aumento 200x; e em (c) e (d) revestimento de TiCN2, aumento 100x.

A Figura 11 apresenta imagens das superfícies obtidas no ensaio de adesão realizadas sobre as amostras revestidas, com isso foi possível avaliar a adesão para os revestimentos TiCN. Embora a norma utilizada seja qualitativa e de caráter interpretativo, indicam que a adesão foi considerada aceitável.

\subsection{Esfera sobre Disco}

Este ensaio é regulamentado pela norma ASTM G99 - 05(2010). O corpo de prova é um disco; este disco fica estático e preso a um suporte, a esfera (presa em dispositivo) serve como contra-corpo no par tribológico e gira. Desta forma, a carga determinada no ensaio é aplicada na direção normal a superfície da amostra e uma trilha de desgaste é impressa no corpo de prova, como pode ser visto esquematicamente na Figura 12.

Para realização dos ensaios de resistência ao desgaste e determinação do coeficiente de atrito foi utilizado um tribômetro da marca CSM. Foi aplicada carga normal à superfície da amostra de $10 \mathrm{~N}$, a velocidade da esfera sobre o disco 

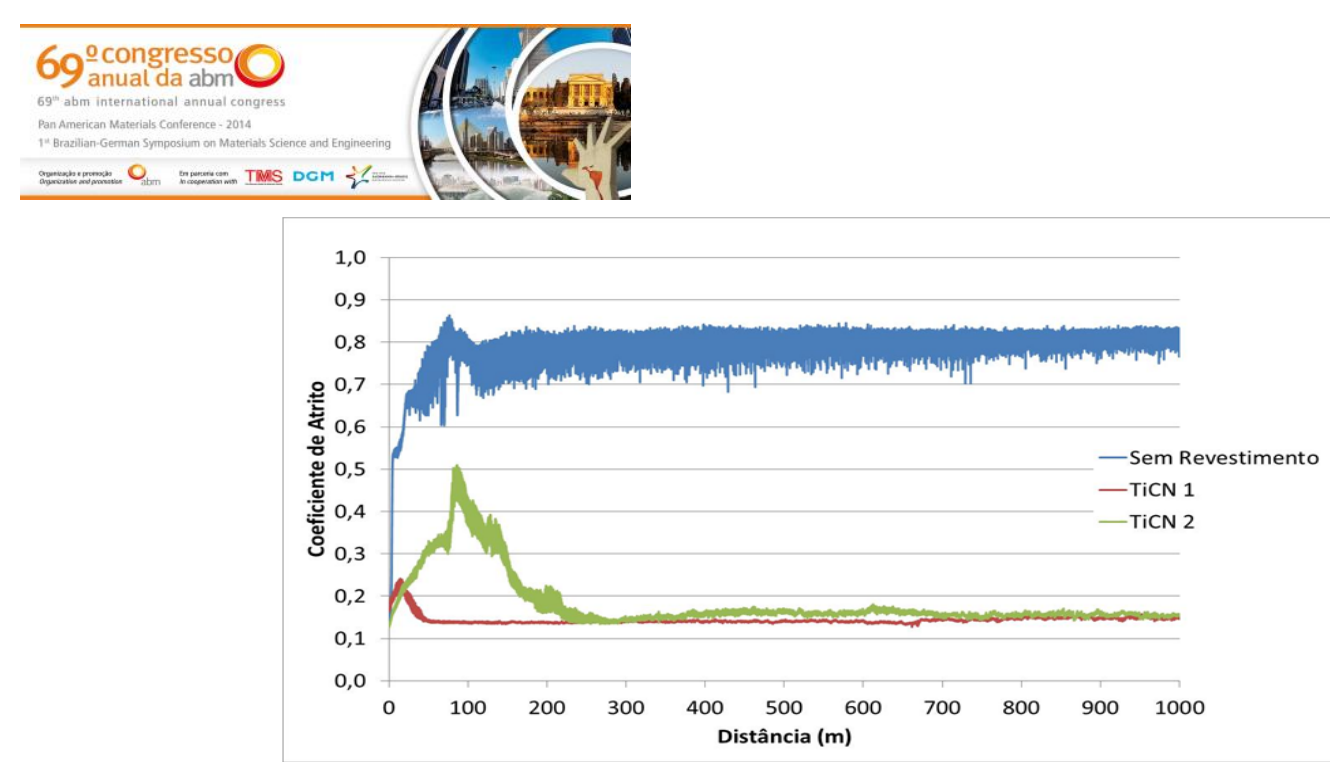

Figura 14. Curvas obtidas no ensaio esfera sobre disco apresentando coeficiente de atrito versus distância percorrida para amostras revestidas e não revestidas.

\subsection{Ensaio de Dobramento sob Tensão}

Para análise pelo ensaio DST, a máquina de ensaio foi instrumentada com células de carga e torquimetro, os quais apresentaram eficientes para o ensaio. Pela Figura 15 pode-se ver a região de atuação onde há o deslizamento da chapa sobre o pino, proporcionando obter a média do torque gerado durante os ensaios.

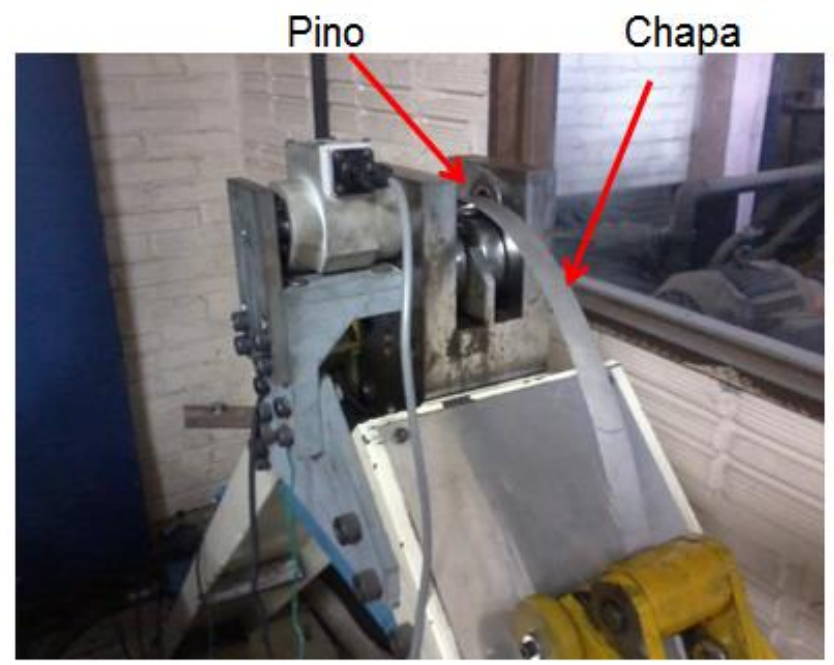

Figura 15. Detalhe do ensaio onde a chapa desliza sobre o pino.

No ensaio DST, foram analisados os valores do revestimento (TiCN1), os quais apresentaram melhores valores no ensaio pino-sobre-disco. Pela Figura 16 pode-se ver que a média do torque gerado durante os ensaios apresentaram uma nítida diferença para cada tratamento avaliado e que houve uma oscilação relativamente pequena no perfil das curvas, possibilitando visualizar essa diferença existente entre cada tratamento. 

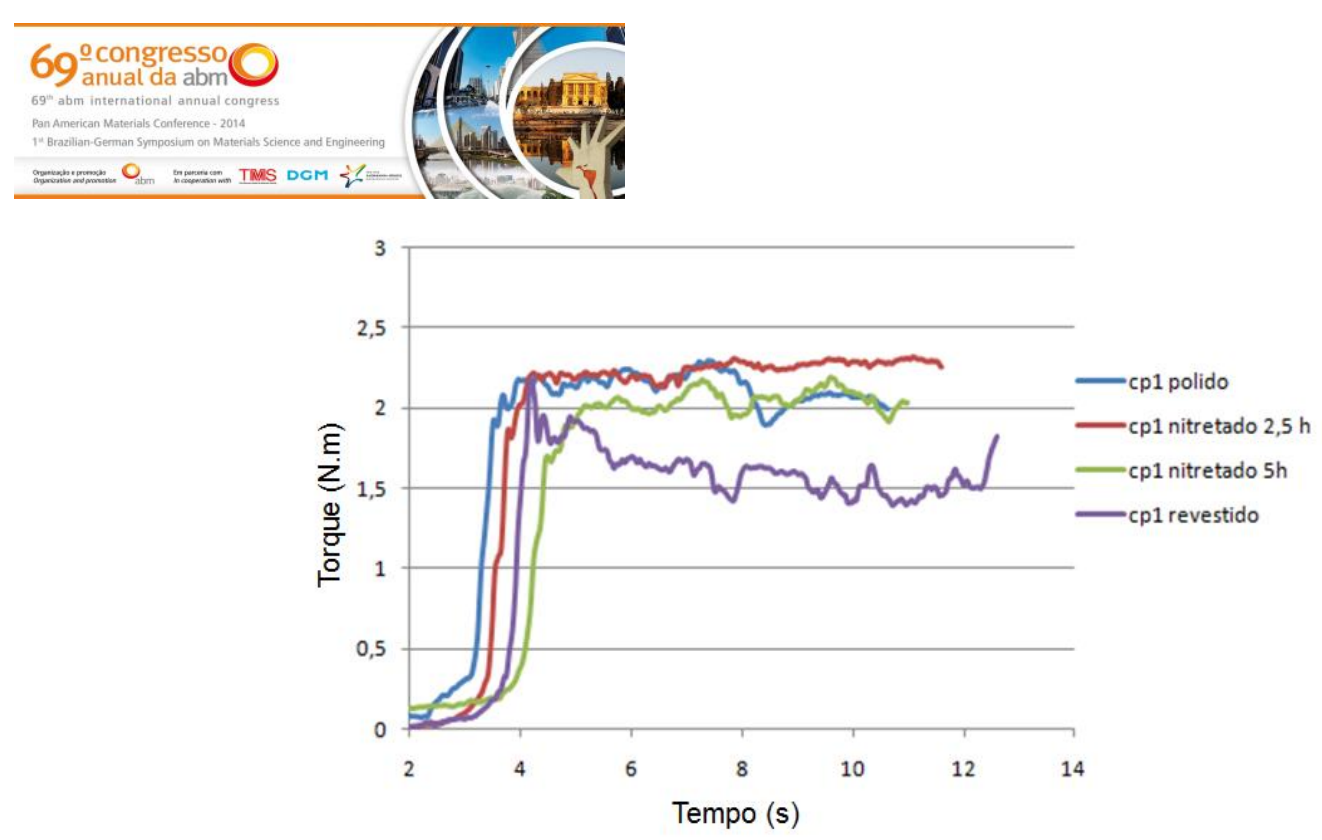

Figura 16. Torque medido para cada tratamento durante o ensaio DST

O resultado mais evidente que se obtém ao se analisar a figura é a redução do valor de torque exigido neste ensaio para o tratamento da amostra que foi revestida com TiCN, o que demonstra que ocorre a redução do coeficiente de atrito em comparação com a amostra polida e a amostra nitretada. Pode-se dizer que as amostras apresentaram um comportamento equivalente entre si e os presentes resultados confirmam o excelente desempenho de filmes de TiCN em sistemas tribológicos sem lubrificantes e para condições de atrito deslizante.

\section{CONCLUSÃO}

As variações nos tempos de nitretação, bem como a inserção de revestimentos de TiCN na superfície do substrato, alteram significativamente a dureza e coeficiente de atrito, possibilitando o aumento de dureza ao mesmo tempo em que melhora levemente o coeficiente de atrito.

Foram obtidas profundidades de camada nitretada de difusão de 60 e $70 \mu \mathrm{m}$ para os parâmetros de processo de nitretação de 2,5 e 5 horas respectivamente.

Foi possível a produção de um revestimento TiCN através do processo de evaporação por arco catódico e, de acordo com medições via GDOES, obteve-se espessura de camada de revestimento de 1,5 e 2,5 $\mu \mathrm{m}$ para tempos de evaporação no processo de deposição de 35 e 80 minutos, respectivamente

Houve aumento da dureza superficial das amostras tanto nitretadas quanto revestidas com TiCN e uma redução do coeficiente de atrito bastante significativa quando se faz uso do revestimento para os ensaios de pino-sobre-disco, comprovando esta redução de atrito no ensaio DST para os pinos nitretados.

O resultado no ensaio DST mostra uma redução do valor de torque exigido neste ensaio para o tratamento da amostra que foi revestida com TiCN, o que demonstra que ocorre a redução do coeficiente de atrito em comparação com a amostra polida e a amostra nitretada.

\section{BIBLIOGRAFIA}

1 Both GB. Caracterização e avaliação tribológica de superfícies resistentes ao desgaste para aplicação em matrizes de conformação a frio. Porto Alegre : Dissertação de Mestrado, 2011. 
2 Kwietniewski C, Fontana W, Moraes C, Rocha AS, Hirsch T, Reguly A. Nitrided layer embrittlement due to edge effect on duplex treated AISI M2 high-speed steel. Surface and coatings Technology, 2004: 27-32.

3 Diesselberg M, Stock H-R, Mayr P. Friction and wear behaviour of PVD chromium nitride supported carbon coatings. Surface and Coatings Technology, 2004: 612-616.

4 Figueiredo MR. Formation mechanisms of low-friction tribo-layers on arc-evaporated TiC1-xNx hard coatings. Wear, 2008; 525-532.

5 Forsich C, Heim D, Mueller T. Influence of the deposition temperature on mechanical and tribological properties of a-C:H:Si coatings on nitrided and postoxided steel deposited by DC-PACVD. Surface and Coatings Technology. 2008; 203.

6 Froehlich AR. Tratamento Superficial DUPLEX com TiN e CrN de Aços Ferramenta da Classe AISI H13 Para Matrizes de Injeção de Ligas de Alumínio. Porto Alegre : Tese de Doutorado, 2003.

7 Hirsch T, Clarke TR, Rocha AS. In-situ study of plasma nitriding . Surface and Coatings Technology. 2007.

8 Karakan M, Alsaran A, Çelik, A. Effect of process time on structural and tribological properties of ferritic plasma nitrocarburized AISI 4140 steel. Materials Desing. 2004.

9 Michler T, et al. Continuously deposited duplex coatings of plasma nitriding and a-C:H:Si deposition. Surface and Coatings Technology, 1999: 41-45.

10 Podgornik B, et al. Wear and friction behavior of duplex-treated AISI 4140 steel. Surface and Coatings Technology, 1999.

11 Podgornik B, Vizintin J, Leskovsek V. Tribological properties of plasma nitrided AISI 4140 steel. Surface and Coatings Technology, 1998.

12 Pye D. ASM American Society for Metals - Pratical Nitriding and Ferritic Nitrocarburizing. 2003. pp. 1-256.

13 Ramos, F. D. Influência das Tensoes Residuais sobre a Difusao de Nitrogênio no Processo Nitretacao a Plasma. Porto Alegre : Dissertacao de Mestrado, 2003.

14 Rocha AS. Influência do Estado Superficial Prévio na Nitretação a Plasma do Aço ABNT M2. Porto Alegre : Tese de Doutorado, 2000.

15 Santos APM. dos. Desenvolvimento e Aplicação de Processos com Plasmas de Alta Densidade para Aplicação de Filmes de Carbono . São Paulo : Tese de Doutorado, 2005.

16 Santos GR. Caracterização de filme de DLC e avaliação dos esforços de usinagem em incertos revestidos no torneamento de ligas Al-Si. Curitiba : Dissertação de Mestrado, 2007.

17 Senna LF. Produção e caracterização de filmes duros de carboneto de titânio. Porto Alegre : Tese de Doutorado, 1998. 